\title{
Parameter Study in CFD simulations of Thermal Blockage by a Water Curtain in a Multi-Compartment Fire Configuration
}

\author{
Ebrahim Zadeh, S. ${ }^{1}{ }^{*}$, Beji, T. ${ }^{1}$, Merci, B $^{1}$ and Butafuoco, H. $^{2}$ \\ ${ }^{1}$ Ghent University-UGent, Department of Flow, Heat and Combustion Mechanics, Ghent, \\ Belgium. \\ ${ }^{2}$ National Institute of Industrial Technology (INTI), Center for research and development on \\ construction, San Martin, Buenos Aires, Argentina. \\ *Corresponding author email: setareh.ebrahimzadeh@ugent.be
}

\begin{abstract}
Thermal blockage by a water curtain to prevent heat and smoke spread from a fire compartment to an adjacent one is studied numerically using a Computational Fluid Dynamics (CFD) code, namely the Fire Dynamics Simulator (FDS5). A two-room compartment connected by an open door is simulated. A $165 \mathrm{~kW}$ pool fire is set up in the fire room. A water curtain is placed near the opening. A sensitivity analysis is performed on the grid size, diameter of droplets, density of droplets introduced in the computational domain and thickness of the curtain. Temperature and average radiative heat flux in the protected compartment are studied. The results of numerical calculations show that the water curtain can be a useful tool for compartmentation in the sense of thermal blockage. As expected, finer droplets are shown to be more efficient. Neither the number of droplets per second introduced in the computational domain, nor the thickness of the curtain (modified by changing the bounds of the solid angle), have a noticeable influence on the thermal blockage. The numerical results are compared against available experimental data.
\end{abstract}

KEYWORDS: Water curtain, thermal blockage, droplets.

\section{NOMENCLATURE}

$d \quad$ droplet diameter $(\mu \mathrm{m})$

$d_{m} \quad$ median volumetric diameter $(\mu \mathrm{m})$

$A_{o} \quad$ orifice area $\left(\mathrm{m}^{2}\right)$

$V \quad$ velocity $(\mathrm{m} / \mathrm{s})$

$\dot{m}_{w} \quad$ water flow rate $(\mathrm{kg} / \mathrm{s})$

$\begin{array}{ll}\text { Greek } & \\ \sigma & \text { empirical constant }(-) \\ \gamma & \text { empirical constant }(-) \\ \rho & \text { density of water }\left(\mathrm{kg} / \mathrm{m}^{3}\right)\end{array}$

\section{INTRODUCTION}

A major concern in case of fire in a compartment is the spread of heat and smoke into the adjacent compartment through the openings. If this problem cannot be solved by technological options such as fire-resistant doors or fire and smoke screens, the use of a water spray curtain (drencher system) can be an option. The main question is, to what extent the water curtain can be efficient for this purpose, in that flame spread or fire spread is avoided.

Chow and Ma [1] investigated this issue by an experiment. It was observed that due to not having a continuous layer discharged from the nozzles, thermal radiation and smoke could not be totally blocked. However, the protected-side was kept cooler. In the research by Fong et al. [2] reduction of the air temperature at the protected side as well as the radiative heat flux at the fire side was observed. The spread of smoke could not be completely stopped. However, the amount of smoke was significantly reduced in the protected side. The same result was obtained by Hirota et al. [3] in the case of reduction of the temperature on the other side of the fire. 
To the authors' knowledge, there are limited experimental and numerical data available regarding the effectiveness of the water curtain as a tool for compartmentation. Therefore, in this paper, this matter is studied numerically using a Computational Fluid Dynamics (CFD) code, namely the Fire Dynamics Simulator (FDS5) [4]. The geometrical configuration (see Fig. 1) consists of two rooms $(2.9 \mathrm{~m} \times 4.0 \mathrm{~m} \times 2.6 \mathrm{~m}$ each $)$ connected by an open doorway $(2.2 \mathrm{~m} \times 1.83 \mathrm{~m})$. A $165 \mathrm{~kW}$ methanol pool fire of $0.6 \mathrm{~m}$ diameter is set up in the fire room. The water curtain is placed near the opening (at $20 \mathrm{~cm}$ ) in the adjacent room. Two thermocouple trees are located on both sides of the opening ( $0.5 \mathrm{~m}$ away from the center of the opening). The nozzle, with an orifice size of $8 \mathrm{~mm}$ and flow rate of $1.49 \mathrm{l} / \mathrm{s}$, is placed above (and $10 \mathrm{~cm}$ away from) the opening in the protected room. It is actuated after 120 seconds. More details on the experimental set-up can be found in $[1]$.

A structured uniform mesh of $10 \mathrm{~cm}$ is used. The experiment duration had been around 850 seconds, although the fire had died out before this time. The simulation time is chosen to be 550 seconds in order to avoid unnecessary computational cost.

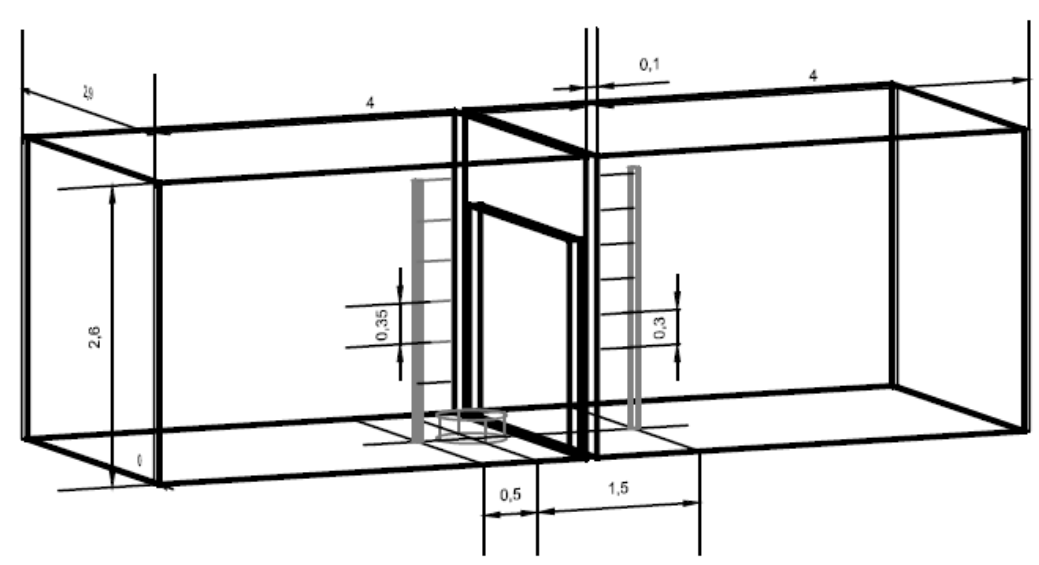

Figure 1. Geometrical configuration [1].

\section{OVERVIEW OF THE NUMERICAL MODEL IN FDS}

FDS5 uses a Lagrangian technique to represent water droplets. This means that each moving droplet is tracked individually. However, since tracking every drop produced by a sprinkler is time and memory consuming, only a limited number of droplets is tracked. Thus, each droplet in FDS represents multiple droplets of similar size and trajectories. All the heat transfer and movement will be calculated based on the single droplet's diameter and temperature and the effect is then multiplied by a weighting factor.

Some important parameters to be considered in the simulations are the following:

Size distribution: In FDS, the median volumetric diameter, $d_{m}$, of the droplets (i.e., half the mass is carried by droplets with diameters of $d_{m}$ or less) is used. The distribution is assumed to be a combination of Rosin-Rammler and log-normal. The default value is $500 \mu \mathrm{m}$. Defaults for minimum and maximum diameters are $20 \mu \mathrm{m}$ and infinitely large $(\infty)$, respectively. The RosinRammler/log-normal distribution is given by [4] 
$F(d)=\left\{\begin{array}{ll}\frac{1}{\sqrt{2 \pi}} \int_{0}^{d} \frac{1}{\sigma d^{\prime}} e^{-\frac{\left[\ln \left(d^{\prime} / d_{m}\right)\right]^{2}}{2 \sigma^{2}} d d^{\prime}} & \left(d \leq d_{m}\right) \\ -0.693\left(\frac{d}{d_{m}}\right)^{\gamma} & \left(d_{m}<d\right)\end{array}\right.$,

where $\gamma$ and $\sigma$ are empirical constants equal to about 2.4 and 0.6 , respectively [5].

For the simulations, the default values for $\gamma$, minimum and maximum droplet diameter are used. The median droplet diameter of $1000 \mu \mathrm{m}$ is chosen (the median volumetric droplet diameter was not mentioned in the experiment).

Density of the droplets: The density of the droplets, i.e., the number of droplets introduced in the computational domain per second, was chosen to be 20000. It is recalled that for a real sprinkler or nozzle, the number of droplets created per second is much greater than the numbers that can be simulated.

Simulation of the water curtain: In FDS5 sprinklers or nozzles discharge water in a conical pattern. In this work, to create a more accurate spray pattern for a drencher system, $T A B L$ input lines were used as [4]

\section{\&TABL ID='table_id',TABLE_DATA=LAT1,LAT2,LON1,LON2,VELO,FRAC}

For the simulation, the spray pattern was defined as 2 jets, each with a flow rate of half of the total flow rate $(\mathrm{FRAC}=0.5)$. To have a spray angle around $180^{\circ} L A T 1$ and $L A T 2$ were chosen to be $0^{\circ}$ and $90^{\circ}$, respectively. For the curtain "thickness" LON1 and LON2 were chosen to be $88^{\circ}$ and $91^{\circ}$ as shown in Fig. 2a. It should be noted that, in order to have a water curtain close to the reality, it was decided not to use a high value for the solid angle $(L O N)$. Figure $2 \mathrm{~b}$ displays a spray pattern discharged from a drencher nozzle with a spray angle around $180^{\circ}$.

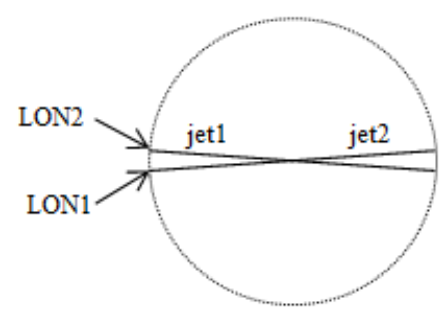

(a)

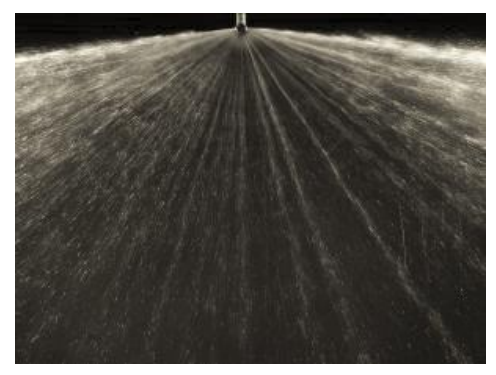

(b)

Figure 2. (a) Top view of the curtain, (b) Spray pattern discharged from a drencher nozzle (spray angle around $180^{\circ}$ ) [1]

The velocity (VELO) of droplets $(\mathrm{m} / \mathrm{s})$ at their point of injection was calculated as

$$
\dot{m}_{w}=\rho A_{o} V \rightarrow V=\frac{\dot{m}_{w}}{\rho A_{o}},
$$

where, $\dot{m}_{w}$ is the water flow rate $(\mathrm{kg} / \mathrm{s}), \rho$ is the density of water $\left(\mathrm{kg} / \mathrm{m}^{3}\right)$ and $A_{o}$ is the orifice area $\left(\mathrm{m}^{2}\right)$. 


\section{Radiation modeling}

In FDS the radiation equation is solved using a finite volume technique. The solver has two modes of operation; a gray gas model (default) and a wide band model [4]. In this work the default model is used. The gray gas model assumes that the gas behaves as a gray medium.

\section{Absorption and scattering of thermal radiation by water droplets}

Water droplets attenuate the radiation by absorption and scattering. Absorption is the pathway to droplet evaporation while scattering redirects incident energy into non-incident directions [7]. The relative importance of these mechanisms depends on the droplet size and the wavelength of the radiation. [10]. In FDS, absorption and scattering characteristics of the water droplets is computed by Mie theory (valid for spherical and isolated droplets) [5]. More details, including the entire radiative transport equation, can be found in [5].

\section{SENSITIVITY ANALYSIS}

The effects of several spray parameters are investigated numerically. The sensitivity analysis on the spray pattern is conducted with respect to

1) The median droplet diameter, $d_{m},(500 \mu \mathrm{m}$ instead of $1000 \mu \mathrm{m})$;

2) The number of droplets per second introduced into the computational domain (40000 instead of 20000); and

3) The thickness of the curtain $\left(4^{\circ}\right.$ instead of $\left.2^{\circ}\right)$.

A grid sensitivity analysis is also carried out (a structured uniform mesh of $5 \mathrm{~cm}$ instead of 10 $\mathrm{cm})$.

\section{COMPLEMENTARY SIMULATIONS}

Two additional simulations have also been carried out in order to investigate 1) the effect of blockage of direct radiation from the fire source and 2) the effect of the water curtain in the stratified case. For the first case, the burner is placed $1 \mathrm{~m}$ further away from the curtain. For the second case, two additional openings, with the same dimensions as the open doorway between the compartments, are added on each side of the chambers (see Fig. 3).

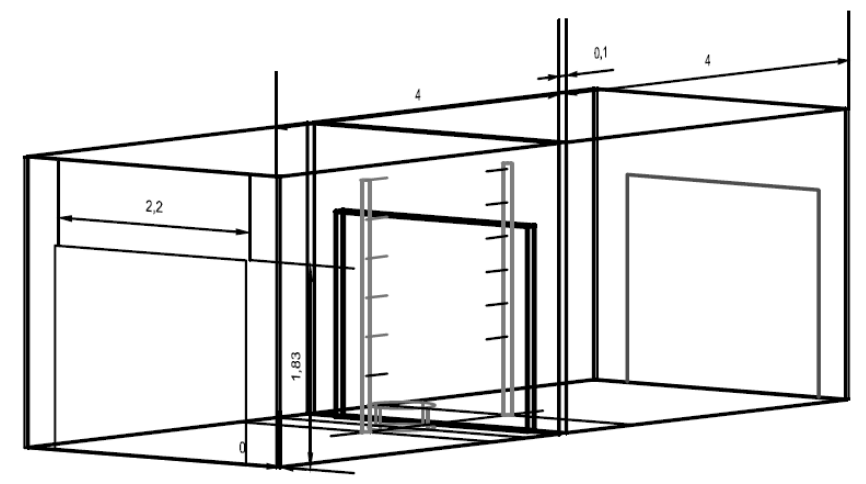

Figure 3. Geometrical configuration for the second complementary simulation 


\section{RESULTS AND DISCUSSION}

\section{Thermal blockage}

As can be seen from Fig. 4, without the water curtain the temperature in the protected side reaches values up to about $120^{\circ} \mathrm{C}$. After injection of the water curtain (at $\mathrm{t}=120$ seconds), the temperature drops in the protected side. Results from the simulation also show that about 50 seconds after discharge of the water curtain, the temperature in the protected room drops from around $120^{\circ} \mathrm{C}$ to below $60^{\circ} \mathrm{C}$. This is in line with the experiment, where a temperature reduction of over $60^{\circ} \mathrm{C}$ is recorded [1]. All the temperature measurements are based on the highest thermocouple placed at $\mathrm{h}=2.2 \mathrm{~m}$ (to have the highest temperature).

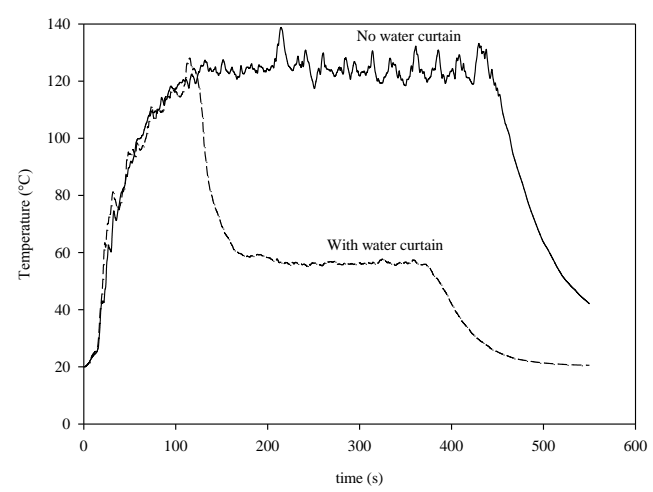

Figure 4. Effect of the water curtain on the temperature in the protected chamber

Figure 5 display the average radiative heat flux (between $t=140 \mathrm{~s}$ and $\mathrm{t}=165 \mathrm{~s}$ ) on the floor at the centerline of the protected room, starting $20 \mathrm{~cm}$ away from the water curtain. The water curtain substantially reduces the heat flux in the protected compartment.

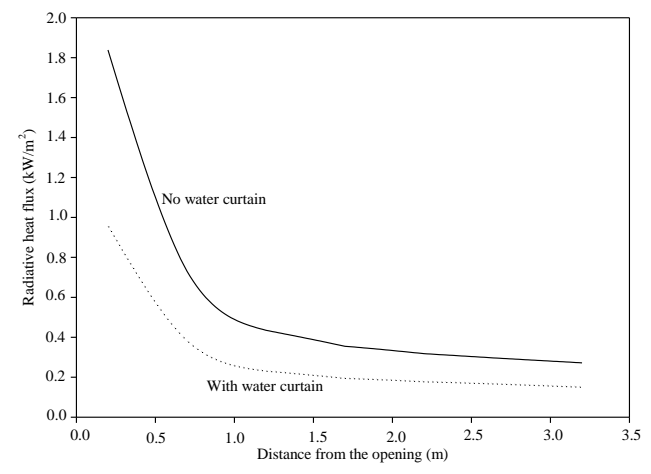

Figure 5. Average radiative heat flux distribution on floor level at the centerline

\section{Smoke spreading}

The amount of soot $(\mathrm{mol} / \mathrm{mol})$ in the protected room is shown in Fig. 6. Whereas the amount of soot increases less rapidly after injection of the water curtain, clearly there is no 'blocking' effect. The spread of smoke through the water curtain has indeed been observed in all cases. However, since the number of droplets introduced in the computational domain is far less than in reality, more investigations should be carried out before reaching final conclusions. Indeed, a 
higher porosity in the simulated curtain, compared to the one in reality, may be a reason for spread of the smoke through the curtain in the simulations. In the experiment, as well, smoke could not be prevented from spreading from the fire room to the protected area [1]. In the literature [1 and 2] the increase of the water flow rate and pressure are suggested in order to provide a more continuous curtain (less porosity).

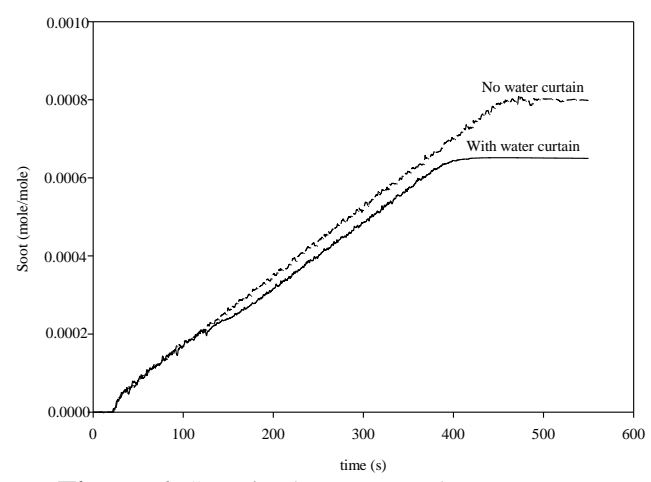

Figure 6. Soot in the protected compartment

\section{Sensitivity analysis}

Figure 7 shows the effect of reducing the droplet diameter on the temperature. As expected, finer droplets are shown to be more efficient. Reducing the droplet diameter from $\mathrm{d}_{\mathrm{m}}=1000 \mu \mathrm{m}$ to $\mathrm{d}_{\mathrm{m}}$ $=500 \mu \mathrm{m}$, additionally, lowers the temperature by about $20^{\circ} \mathrm{C}$.

It should be emphasized that in reality, for a given flow rate, the number of droplets increases as the diameter decreases. This will lead to a more continuous curtain. In the simulation, in order to investigate the effect of droplet size, only the median volumetric droplet diameter was changed.

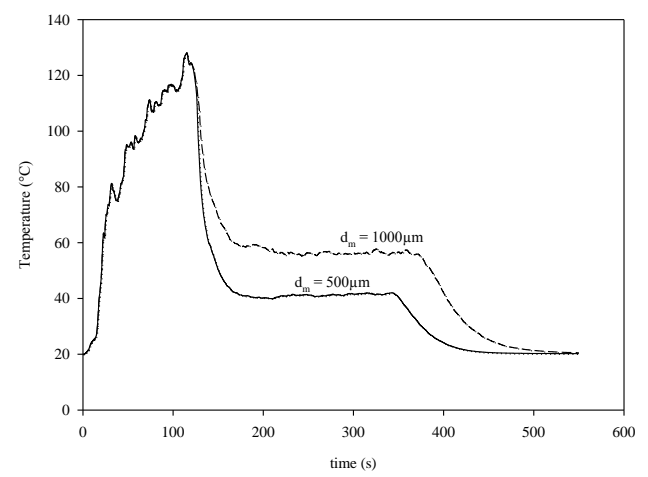

Figure 7. Effect of the droplet size on the temperature of the protected chamber

Figure 8 displays the comparison between the water curtain in the experiment, and the simulated water curtain with median volumetric droplet diameter of $1000 \mu \mathrm{m}$ and $500 \mu \mathrm{m}$ (left to right). 

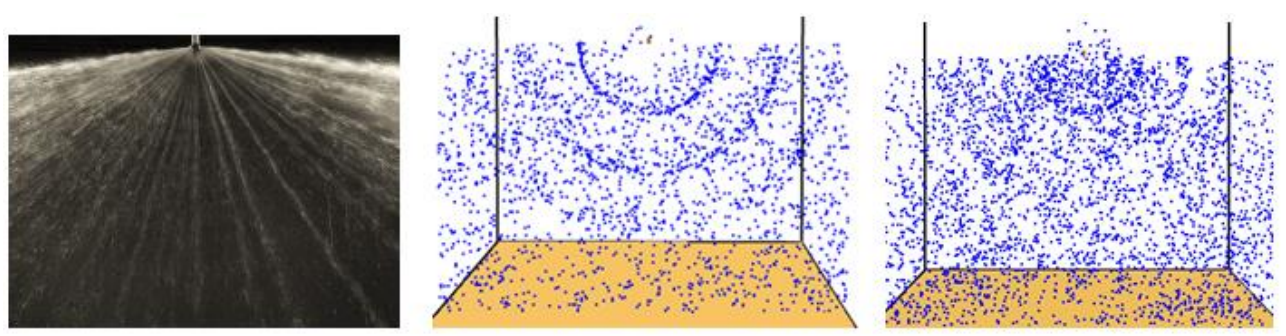

Figure 8. Comparison between the water curtains from the experiment and the simulations, $1000 \mu \mathrm{m}$ and $500 \mu \mathrm{m}$, (left to right).

Figures 9 and 10 depict the effect of finer grid, density of droplets introduced in the computational domain and the thickness of the curtain on the temperature of the protected room at the $2.2 \mathrm{~m}$ height. As can be seen in Fig. 9, no significant difference in the results is observed with the finer mesh. Increasing the density of droplets from 20000 per second to 40000 per second, does not have a noticeable influence on the thermal blockage, either (see Fig. 10a). The same result is observed with increasing the thickness of the curtain from $2^{\circ}$ to $4^{\circ}$ (see Fig. 10b).

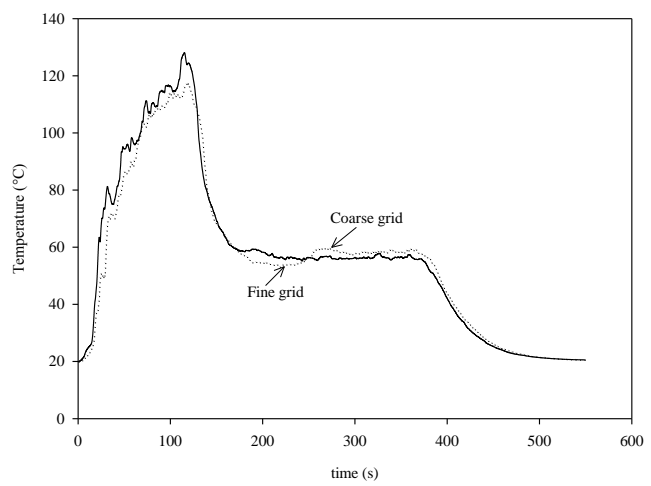

Figure 9. Effect of two different grid sizes on the temperature of the protected chamber

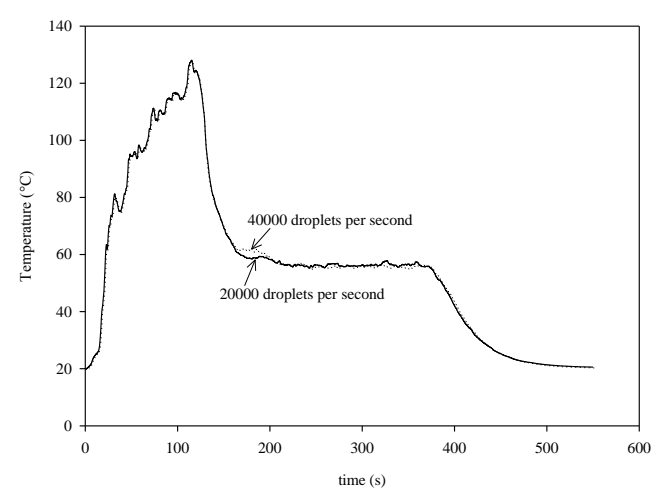

(a)

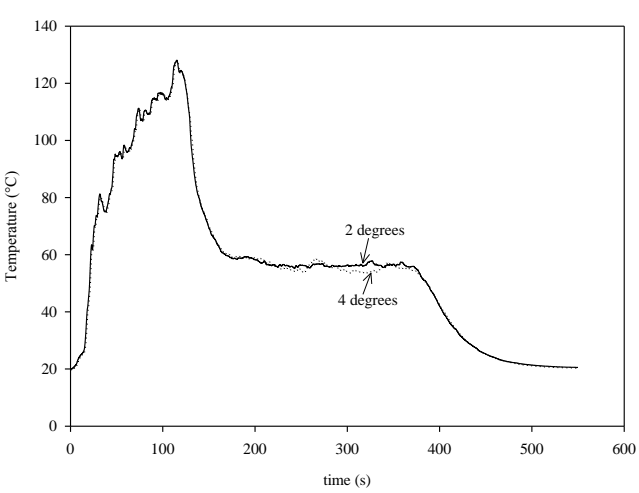

(b)

Figure 10. Temperature profile of the protected chamber for (a) two different droplet densities and (b) two different water curtain thicknesses. 


\section{Complementary simulations}

\section{Replacement of the burner}

In order to examine the effect of the blockage of direct radiation from the fire source, an additional simulation is performed with the burner placed $1 \mathrm{~m}$ further away from the curtain. Several heat flux devices are put on the floor in the centerline of the protected room, at $0.2 \mathrm{~m}, 0.7$ $\mathrm{m}, 1.2 \mathrm{~m}, 2.2 \mathrm{~m}$ and $3.2 \mathrm{~m}$ after the curtain. Table 1 displays the results for the average net heat flux (between $t=140 \mathrm{~s}$ and $\mathrm{t}=165 \mathrm{~s}$ ) for both cases. The results show that placing the burner further away from the curtain does not decrease the heat flux received on the floor in distances of $1.2 \mathrm{~m}$ or further. The effect of direct radiation from the fire is only significant in its vicinity (decrease of around $40 \%$ in the heat flux at $0.2 \mathrm{~m}$ ).

Table 1. Average net heat flux $\left(\mathrm{kW} / \mathrm{m}^{2}\right)$ received on the floor at the centerline of the protected compartment

\begin{tabular}{lcrrrr}
\hline Distance from the curtain & $\mathrm{d}=0.2 \mathrm{~m}$ & $\mathrm{~d}=0.7 \mathrm{~m}$ & $\mathrm{~d}=1.2 \mathrm{~m}$ & $\mathrm{~d}=2.2 \mathrm{~m}$ & $\mathrm{~d}=3.2 \mathrm{~m}$ \\
\hline Original place & 1.52 & 0.92 & 0.69 & 0.53 & 0.48 \\
1 m Further & 0.92 & 0.81 & 0.69 & 0.53 & 0.47 \\
\hline
\end{tabular}

As discussed before, the reduction of over $60^{\circ} \mathrm{C}$ in the temperature of the protected compartment at the $2.2 \mathrm{~m}$ height was observed. Figure 11 displays the comparison between the temperature profiles for both cases. As can be seen, no siginificant change in the results after injection of the water curtain is observed. Although the burner is one meter further away from the water curtain, the temperature profile for both cases is almost the same. It can be concluded that the observed decreased in the temperature of the protected compartment is mainly due to the convective heat exchange between the spray and the hot gases leaving the fire compartment and not shielding of the radiative flux from the pool fire. Considering the small size of the fire (short flame height) these results are not surprising.

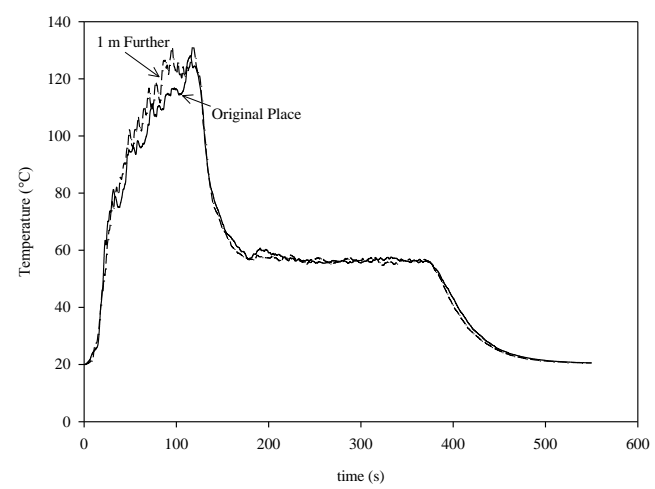

Figure 11. Temperature profile of the protected chamber for two different places of the fire source

\section{Two additional openings}

As expected, for the case with two extra openings, a clear two-layer pattern was formed before injection of the water curtain (see Fig. 12). A few seconds after injection of the curtain, circulation of smoke in the protected room was observed due to the airflow induced by the water 
curtain. The protected room was filled up with the smoke (see Fig. 13). Figure 14 shows the results for the temperature profile. An almost uniform temperature of around $40^{\circ} \mathrm{C}$ was observed.

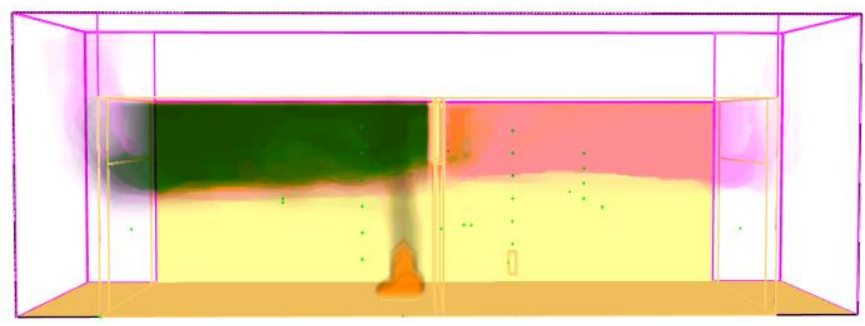

Figure 12. Smoke pattern before injection of the water curtain

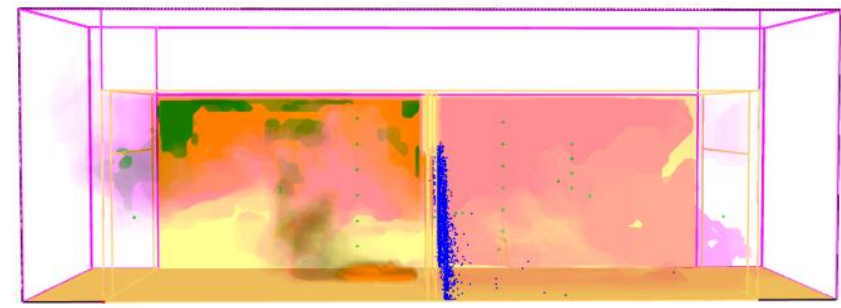

Figure 13. Smoke pattern after injection of the water curtain

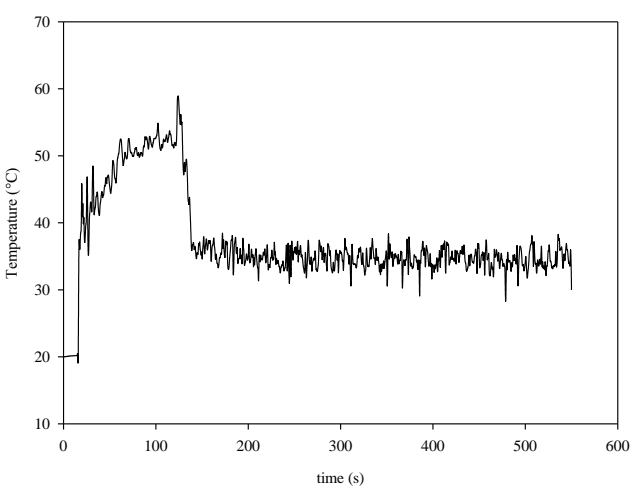

(a)

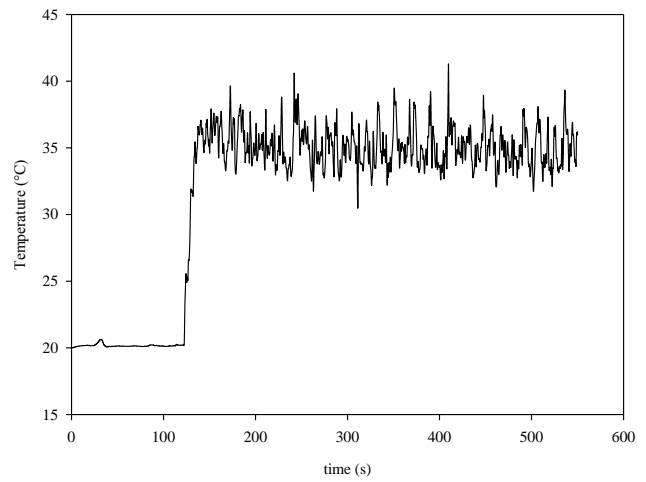

(b)

Figure 14. Temperature profile in the protected compartment: (a) lower layer, (b) upper layer 


\section{CONCLUSIONS}

The use of a water curtain as a tool for compartmentation has been studied numerically. The effect of several spray pattern parameters has been investigated. In terms of thermal blockage the following can be concluded:

- The water curtain can be a useful tool for compartmentation to provide thermal blockage.

- Finer droplets are shown to be more efficient.

- Neither the density of droplets introduced in the computational domain, nor the thickness of the curtain, has a noticeable influence on the thermal blockage.

- For the case considered (with a relatively small fire), the reduction in temperature in the protected compartment after activation of the water spray, is due to convective heat exchange, not due to shielding of direct radiation from the fire.

- In the stratified case, injection of the water sprays leads to mixing of the two zones and eventually smoke fills up the compartment (resulting in an almost uniform temperature).

Having a continuous water layer is the key point in the blocking of smoke [1 and 2]. In FDS, creating such a pattern does not seem feasible due to limitations in defining the density of droplets in the computational domain. Therefore, regarding the spread of smoke, no specific conclusion can be provided from the study as performed.

\section{ACKNOWLEDGMENTS}

This research was partly funded by the Scientific Fund for Research - Flanders (Belgium) (FWO-Vlaanderen) through project G.0049.12.

\section{REFERENCES}

1. Chow, W. K., Ma, and E. Y. L., "Experimental Studies on Thermal and Smoke Blockage by Water Curtains," Joint Thermodynamics and Heat Transfer Conference, California 2006.

2. Fong, N. K., Chow, W. K., and Chan,W. T., "Preliminary Studies on Smoke Spreading Prevention and Thermal Radiation Blockage by a Water Curtain," International Journal on Engineering PerformanceBased Fire Codes 3: 98-103 (2001).

3. Hirota, M., Mizuochi, H., and Ikeda, K., "Experimental Study on the Fire-Spreading Prevention Effect in Buildings by Drencher Equipment," Fire Science and Technology 23: 222-239 (2004).

4. McGrattan, K., McDermott, R., Hostikka, S., and Floyd, J., "Fire Dynamics Simulator (Version 5) User's Guide," NIST Special Publication 1019-5, 2010.

5. McGrattan, K., Hostikka, S., Floyd, J., Baum, H., Rehm, R., Mell, W., and McDermott, R., "Fire Dynamics Simulator (Version 5) Technical Reference Guide," National Institute of Standards and Technology (NIST) 2010.

6. Fong, N. and Chan, W., "On the Properties of a Water Curtain Discharged From a Drencher System," International Journal on Engineering Performance-Based Fire Codes 3: 87-91 (2001).

7. Modest, M. F., Radiative Heat Transfer, Academic Press, 2003.

8. Yang, W., Parker, T., Ladouceur, H., and Kee, R. J., "The Interaction of Thermal Radiation and Water Mist in Fire Suppression," Fire Safety Journal 39: 41-66 (2004).

9. Tang, Z., Vierendeels, J., Fang, Z., and Merci, B., "Description and Application of an Analytical Model to Quantify Downward Smoke Displacement Caused by a Water Spray," Fire Safety Journal 55: 50-60 (2013).

10. Hostikka, S. and McGrattan, K., "Numerical Modeling of Radiative Heat Transfer in Water Sprays," Fire Safety Journal 41: 76-86 (2006). 